\title{
Application of seismic prospecting to determine the width of influence of surface faults associated to land subsidence - a case of study in the Aguascalientes Valley, México
}

\author{
Hugo Luna-Villavicencio ${ }^{1}$, Jesús Pacheco-Martínez ${ }^{2}$, Fernando Acuña-Lara ${ }^{1}$, \\ Martín Hernández-Marín ${ }^{2}$, and Norma González-Cervantes ${ }^{2}$ \\ ${ }^{1}$ Doctorado en Ciencias de los Ámbitos Antrópicos, Universidad Autónoma de Aguascalientes, \\ Aguascalientes, México \\ ${ }^{2}$ Departamento de Ingeniería Civil, Centro de Ciencias del Diseño y de la Construcción, \\ Universidad Autónoma de Aguascalientes, Aguascalientes, México \\ Correspondence: Hugo Luna-Villavicencio (inghugolunavillavicencio@gmail.com)
}

Published: 22 April 2020

\begin{abstract}
Aguascalientes valley, located in the central part of México, is affected for a land subsidence process triggered by groundwater withdrawal since the 1980's. Currently, the occurrence and the reactivation of surface faults and earth fissures due to differential subsidence, is the main concern for government bureaus dealing with urban planning, because of the damages that these terrain discontinuities are able to cause in constructions and infrastructure. The deformation and rupture process produces an active linear discontinuity with a variable width of influence, where the constructions and infrastructure are prone to get damage. Therefore, the determination of this width of influence is critical for urban planning and hazard determination.

In this work, the results of a geophysical seismic survey carried out in six surface discontinuities located in the subsidence area of the Aguascalientes Valley, are presented and discussed. The study included acquisition of seismic tomography profiles measured perpendicularly to the discontinuities, in order to obtain the P-wave velocity sections. The resulted P-wave velocity models show a low-velocity anomaly within the fracture trace with widths from 50 to $100 \mathrm{~m}$. This anomaly is interpreted as a mechanically disturbed zone due to the activity of the surface fault, this is, due to the presence of fracturing caused to the adjacent material by the differential subsidence. The results suggest that the material in the disturbed zone, is experiencing a increase in secondary porosity, caused by the deformation and rupture process, and the subsequent generation of small fissures and voids.

The results of this study have practical implications because the methodology allows defining the influence zone of an active discontinuity, and therefore, to establish a restricted width along the surface discontinuity. The definition of this restraint zone is a first step to produce a subsidence hazard zoning including not only the discontinuity trace but its width of influence.
\end{abstract}




\section{Introduction}

The overexploitation of groundwater from granular aquifers causes a decrease in the elevation of the land surface. This problem is known as land subsidence and is accompanied by differential settlements, which represent a threat to construction and infrastructure, since land subsidence can cause large economic losses.

Land subsidence cases have been documented in different countries, for example in Mexico, Japan, the United States, China, Italy, Iran and Indonesia. Several cities in these countries have reported problems related to subsidence as damages to constructions and infrastructure due to terrain fractures, as well as floods due to changes in surface level (Holzer and Johnson, 1985; Galloway and Burbey, 2011).

In Mexico, several cities present an progressive subsidence process; some of the most affected cities are Mexico City, Querétaro, San Luis Potosí and Aguascalientes (Chaussard et al., 2014; Pacheco-Martínez et al., 2006, 2013).

According to Holzer (1984) terrain discontinuities related to subsidence can be classified in surface faults or fractures. Surface faults are those in which there is vertical and horizontal displacement with the formation of a surface scarp, while fractures have only horizontal displacement and they do not develop scarp. In addition, terrain discontinuities can be differentiated in four types due to their origin and behavior: (a) Ground failures related to land subsidence, are those that did not exist before the process of groundwater extraction, and they were generated due to differential subsidence; (b) Ground failures related to reactivation of paleochannels, are those associated with the removal of fine material (silt, sand) due to subsurface flow, with the formation and collapse of cavities in the trajectory of old buried streams. (c) Tectonic fault and cracks reactivated due to differential subsidence associated to groundwater pumping, are those tectonic faults and cracks affected the aquifer sediments and have been reactivated due to the subsidence process; (d) faults and cracks affecting the aquifer sediments generated before the groundwater exploitation but remain inactive even though the subsidence process is occurring.

On the other hand, the stripe of the main terrain discontinuity, where buildings and infrastructure is damaged by differential settlements, has been named as affectation width of the fault (Figueroa-Miranda et al., 2018), influence zone of the fault (Avila-Olivera and Garduño-Monroy, 2008), fault zone width (Hernández-Marín and Burbey, 2009) and active zone of the fault (Pacheco-Martínez et al., 2015) (Fig. 1).

The width of the influence zone can vary from one or two meters up to a few tens of meters. This width can vary even in the same fault along its trace. Therefore, it is of interest to the persons in charge of urban planning, to have a methodology to measure "in situ" the width of affectation to avoid the construction of infrastructure on this area, or to take the appropriate design considerations knowing the risk that building over the active zone implies.

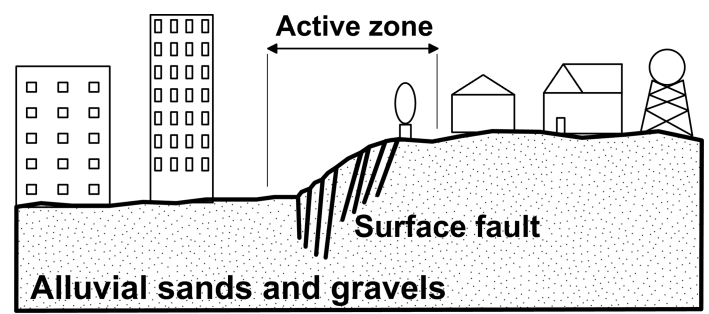

Figure 1. Scheme showing the active zone, which is the strip of mechanical disturbing caused by the main terrain discontinuity, where buildings and infrastructure can suffer damaged by differential subsidence.

This paper presents the results of an investigation to determine the active zone of faults and fissures, based on the propagation of the seismic waves. The results show that the seismic wave velocity decreases when it propagates through the active zone, which was interpreted as an effect of the area where the subsoil material has been weakened due to the fault activity, thereby decreasing its mechanical resistance. The results are presented in graphs of distance versus time, with which it is possible to define the width of the trace of the active zone.

\section{Study area}

The Aguascalientes Valley is located in the center of Mexico $400 \mathrm{~km} \mathrm{NW}$ of Mexico City (Fig. 2). It is located in a tectonic graben delimited by two normal faults with NS orientation that has been filled by volcanoclastic sediments, as a consequence, the aquifer system is formed by unconsolidated alluvial and fluvial materials reaching up to $400 \mathrm{~m}$ according to some wells drilled for pumping freshwater, but it can be deeper in some valley areas as showed by geophysical logs (UAQ-UNAM, 2002).

The filling was deposited over a rocky stratum of irregular topography, which was shaped by the tectonism of the tertiary that also affected part of the unconsolidated sediments of the filling, thus favoring the generation of differential subsidence and associated surface faults, as well as the reactivation of ancient faults and fractures (Pacheco-Martínez et al., 2013; Hernández-Marín et al., 2015). Several cities and towns are located inside the valley, stands out for its urban area the conurbation of the city of Aguascalientes, Jesús María and San Francisco de los Romos, where 1044049 inhabitants are concentrated (INEGI, 2015).

The land subsidence triggered by groundwater extraction has been occurred in Aguascalientes probably since the 1980 s, according to reports of the first fractures observed in the valley (Aranda-Gómez, 1989); however, the subsidence of the valley was measured until 1995 by a permanent GPS station installed at the south of the city of Aguascalientes. The records show subsidence rates up to $180 \mathrm{~mm} \mathrm{yr}^{-1}$ for 1995 to 2000 , decreasing to a rate of $55 \mathrm{~mm} \mathrm{yr}^{-1}$ between 


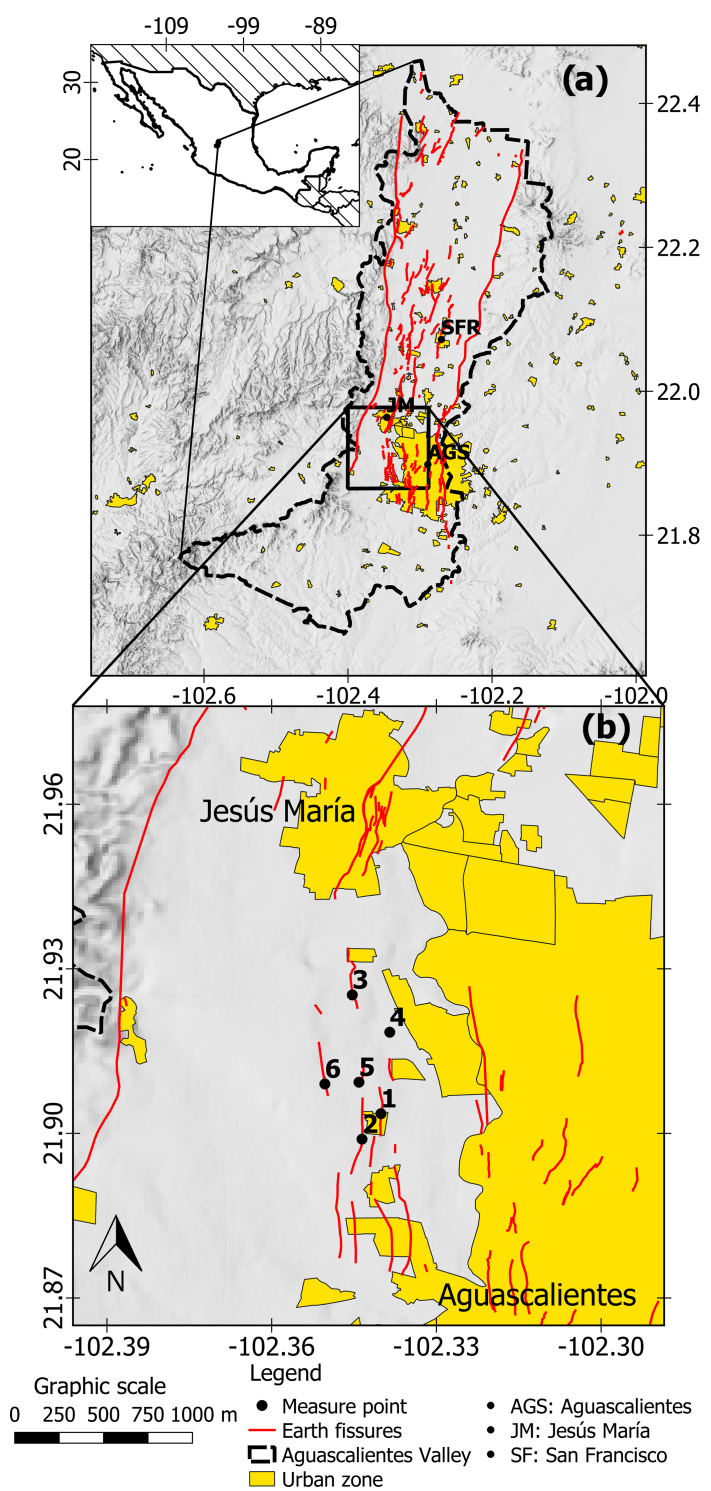

Figure 2. Study area showing the six studied points over ground discontinuities, in (a) the black dotted line is the Aguascalientes valley border.

2000 and 2010, and decreasing even more to $20 \mathrm{~mm} \mathrm{yr}^{-1}$ between 2010 and 2015 (Pacheco-Martínez et al., 2015).

In the Aguascalientes valley, 207 active faults and fractures have been reported in nine municipalities with a total length of $321159 \mathrm{~m}$. Their scarps reach $1.5 \mathrm{~m}$ and have a width at naked eye up to $4 \mathrm{~m}$ (Pacheco-Martínez et al., 2013).

The study area is located to the south west of the Aguascalientes valley. This area has been characterized by a high density of discontinuities, and a current large urban development; this makes it a medium-term risk zone, in which the identification and definition of potential hazard zones is necessary (Fig. 2b). The six point of study showed in Fig. 2b are described as follows:
Site one, is located in the Ejido San Ignacio fault, which is presented as a discontinuous alignment of holes, with a $0.15 \mathrm{~m}$ scarp and an active zone close to six meters wide according to observed damages in the pavement of a road.

Site two, was located on the fault Ex hacienda de San Ignacio, here the fault presents an escarp close to $0.90 \mathrm{~m}$ high, with an influence zone of approximately $10.0 \mathrm{~m}$ width determined by means of observation of damages in constructions.

Site three is located on the Pocitos fault. On this site, since there was an early warning of the presence of the fault, the buildings and houses were located outside the active zone, but the street was not. Hence, it was not possible to define the width of affectation zone of the fault due to the absence of damage. However, some differential subsidence already appears on the pavement of the streets.

Site four. It was studied to verify the probable continuation of the Pocitos fault. The studied site is at the front of the trace of the fault. Since there are neither constructions nor streets in the zone, only a small escarp on the terrain could be observed, suggesting the spreading of Pocitos fault untill this point.

Site five is at the end of the Rancho la Estrella III fault. This fault does not present a clear zone of affectation because the road has a great deterioration in the pavement that masks the active zone of the fault. However, it is possible to observe a small scarp of $0.15 \mathrm{~m}$ high.

Site six is located on the Rancho la Estrella 2 fault. This site shows a well-defined escarpment of $0.15 \mathrm{~m}$ high, and an active area of approximately $5 \mathrm{~m}$.

\section{Methodology}

The wave velocities across the fault were determined from seismic profiles to detect changes in the velocity of seismic wave propagation at different distances from the trace of the discontinuities observed at the naked eye. Each seismic profile included three arrangements of 24 geophones of $4.5 \mathrm{~Hz}$ separated at $2 \mathrm{~m}$. Seismic waves were generated hitting with a 10-pound hammer a steel plate placed on the terrain surface between geophones 6 and 7,13 and 13,18 and 19, also at one meter before the first geophone and one meter after the last (Fig. 3).

\section{Results}

The results obtained show anomalies in the P-wave travel pathway in all the studied sites. It is observed that there 


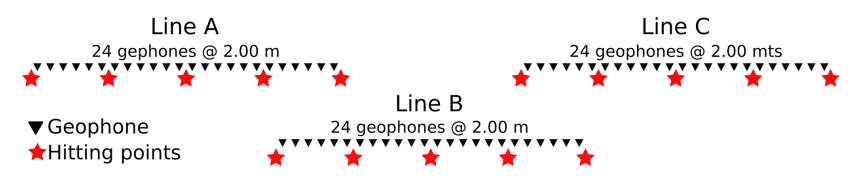

Figure 3. Implemented arrangement for the measurements across the ground discontinuities.
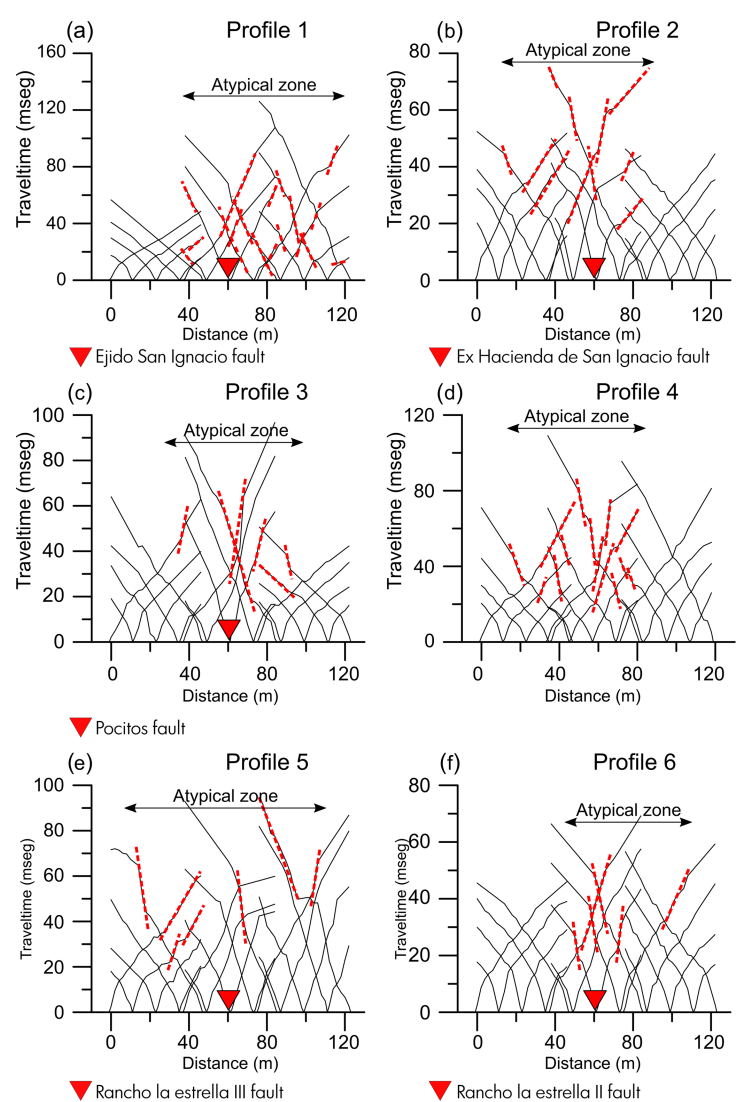

Figure 4. Domocrones of the six studied sites. Red dotted lines indicate the anomalous low-velocity of seismic waves propagation.

are sections where seismic velocity decreases, noticed by increasing slope.

The obtained seismograms were analyzed to pick the firstbreak of each geophone associated with the arrival of direct seismic wave, and with them elaborating a domocrone, that is a time versus distance graph of the entire arrangement. Rising of the graph slope of the wave path, at both sides the ground discontinuity (Fig. 4).

\section{Discussion of results}

In all the sites, the low-speed wave zones are close to the ground discontinuity, which was interpreted as ground ruptures is caused by differential subsidence.

The presence of discontinuities such as micro-cracks in rocky materials contribute to a decrease in the soil density.

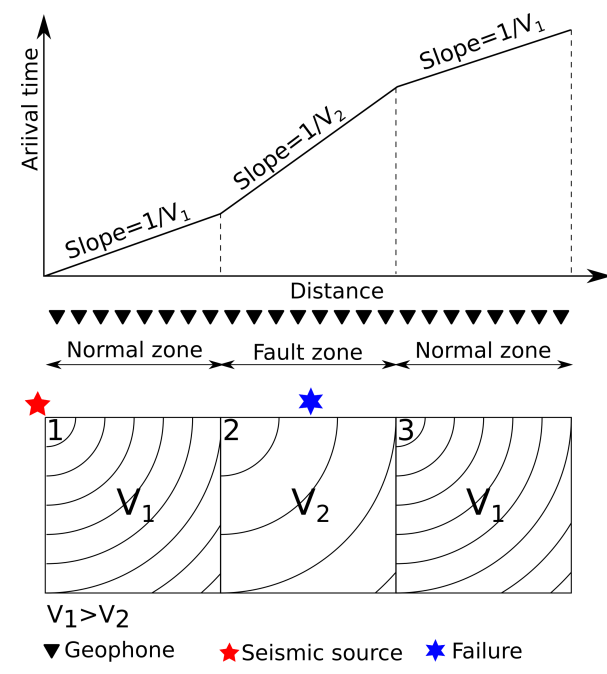

Figure 5. Conceptual sketch of propagation of direct seismic waves through a ground discontinuity.

According to Gardner et al. (1974), the density ( $\rho$ ) of rocky materials is directly proportional to the fourth root of $V_{p}$, both factors are related as shown in Eq. (1):

$\rho=0.31 V_{p}^{\frac{1}{4}}$

Hence, the decrease in the velocity of propagation of the seismic wave can be related to a density decrease of the material adjacent to the discontinuity, caused by the generation of secondary fractures and microfractures as the discontinuity causes soil deformation. Figure 5 shows a conceptual scheme of the change in the seismic wave propagation velocity due to the presence of a ground discontinuity. The figure shows that the waves propagate through block 1 with a velocity V1; and then to $\mathrm{V} 2$ in block 2 (disturbed zone), and then returning to V1 in block 3. In this diagram, block 2 represent the disturbed zone, therefore, $\mathrm{V} 2$ is lower than $\mathrm{V} 1$.

In all the cases, the low-velocity anomaly zone resulting from seismic measurements was faster than the zone where damages to constructions and to the infrastructure were observed with the naked eye. This could be explained considering that although the subsoil is disturbed and weakened by the effects of differential subsidence in the area adjacent to the damaged constructions zone, there, the ground surface deformation is unable to cause distortions large enough to damage constructions, but it is detected as an disturbed zone of soil by the method here presented.

The presence of two parallel discontinuities is not discarded in sites 1 and 5 which present an anomaly wider than the other studied sites, nonetheless, direct exploration by means of trenches is needed to confirm all these interpretations. 


\section{Conclusions}

Results suggest that surface faults and fractures related to land subsidence or reactivation of paleochannels generate a zone of disturbed material adjacent to the main discontinuity. In this zone the velocity of propagation of the seismic wave decreases. This zone is wider than the influence zone of the fault, where constructions and infrastructure is damaged by the differential subsidence. The method can be applied as an approximation to determine the zone where constructions and infrastructure can be potentially damaged due to the existence of land subsidence related terrain discontinuities.

The presented novel method needs more research by means of direct exploration to confirm the results and interpretations.

Data availability. You cand find the data of this research in the Supplement.

Supplement. The supplement related to this article is available online at: https://doi.org/10.5194/piahs-382-781-2020-supplement.

Author contributions. HLV: method conceptualization, data acquisition, and writing. JPM, MHM and NGC: method conceptulization, and writing. FAL: Data acquisition support.

Competing interests. The authors declare that they have no conflict of interest.

Special issue statement. This article is part of the special issue "TISOLS: the Tenth International Symposium On Land Subsidence - living with subsidence". It is a result of the Tenth International Symposium on Land Subsidence, Delft, the Netherlands, 17-21 May 2021.

Acknowledgements. Hugo Luna-Villavicencio and Fernando Acuña-Lara are thankful to CONACyT for financial support.

Financial support. This research has been supported by the Consejo Nacional de Ciencia y Tecnología (grant no. Becas nacionales).

\section{References}

Aranda-Gómez, J. J.: Geología preliminar del Graben de Aguascalientes, ResearchGate, 8, 22-32, 1989.

Avila-Olivera, J. A. and Garduño-Monroy, V. H.: A GPR study of subsidence-creep-fault processes in Morelia, Michoacán, Mexico, Eng. Geol., 100, 69-81, https://doi.org/10.1016/j.enggeo.2008.03.003, 2008.
Chaussard, E., Wdowinski, S., Cabral-Cano, E., and Amelung, F.: Land subsidence in central Mexico detected by ALOS InSAR time-series, Remote Sens. Environ., 140, 94-106, https://doi.org/10.1016/j.rse.2013.08.038, 2014.

Figueroa-Miranda, S., Tuxpan-Vargas, J., Ramos-Leal, J. A., Hernández-Madrigal, V. M., and Villaseñor-Reyes, C. I.: Land subsidence by groundwater over-exploitation from aquifers in tectonic valleys of Central Mexico: A review, Eng. Geol., 246, 91-106, https://doi.org/10.1016/j.enggeo.2018.09.023, 2018.

Galloway, D. L. and Burbey, T. J.: Review: Regional land subsidence accompanying groundwater extraction, Hydrogeol. J., 19, 1459-1486, https://doi.org/10.1007/s10040-011-0775-5, 2011.

Gardner, G. H. F., Gardner, L. W., and Gregory, A. R.: Formation velocity and density; the diagnostic basics for stratigraphic traps, Geophysics, 39, 770-780, https://doi.org/10.1190/1.1440465, 1974.

Hernández-Marín, M. and Burbey, T. J.: The role of faulting on surface deformation patterns from pumping-induced groundwater flow (Las Vegas Valley, USA), Hydrogeol. J., 17, 1859-1875, https://doi.org/10.1007/s10040-009-0501-8, 2009.

Hernández-Marín, M., González-Cervantes, N., and PachecoMartínez, J.: Discussion on the origin of surface failures in the Valley of Aguascalientes, México, Proc. Int. Assoc. Hydrol. Sci., 372, 235-238, https://doi.org/10.5194/piahs-372-235-2015, 2015.

Holzer, T. L.: Ground failure induced by graund-water withdrawal from unconsolidated sediment, Geol. Soc. Am., VI, 67-104, 1984.

Holzer, T. L. and Ivan Johnson, A.: Land subsidence caused by ground water withdrawal in urban areas, GeoJournal, 11, 245255, https://doi.org/10.1007/BF00186338, 1985.

INEGI: INEGI, available at: http://cuentame.inegi.org.mx/ monografias/informacion/ags/poblacion/ (last access: 28 August 2019), 2015

Pacheco-Martínez, J., Arzate, J., Rojas, E., Arroyo, M., Yutsis, V., and Ochoa, G.: Delimitation of ground failure zones due to land subsidence using gravity data and finite element modeling in the Querétaro valley, México, Eng. Geol., 84, 143-160, https://doi.org/10.1016/j.enggeo.2005.12.003, 2006.

Pacheco-Martínez, J., Hernandez-Marín, M., Burbey, T. J., González-Cervantes, N., Ortíz-Lozano, J. Á., Zermeño-deLeón, M. E., and Solís-Pinto, A.: Land subsidence and ground failure associated to groundwater exploitation in the Aguascalientes Valley, México, Eng. Geol., 164, 172-186, https://doi.org/10.1016/j.enggeo.2013.06.015, 2013.

Pacheco-Martínez, J., Cabral-Cano, E., Wdowinski, S., HernandezMarín, M. H., and Zermeño-de-León, M. E.: Application of InSAR and Gravimetry for Land Subsidence Hazard Zoning in Aguascalientes, Mexico, Remote Sens., 7, 17035-17050, https://doi.org/10.3390/rs71215868, 2015.

UAQ-UNAM: Estudio integral sobre la problemática del agua, subsidencia y sismicidad en el valle de Aguascalientes, Informe técnico final preparado por el DEPFI de la UAQ y el CGEO de la UNAM para el Instituto del Agua del estado de Aguascalientes, INAGUA, Aguascalientes, México, 2002. 